\title{
Postpartum depression and health related quality of life: a necessary assessment
}

\begin{abstract}
Maternal postpartum depression has a deleterious effect on the mother and child. The study aimed to assess the prevalence of postpartum depression (PPD) and its determinants, and to examine the relationship between PPD and health related quality of life (HRQOL) among women in Kuwait. A cross-sectional study was conducted in 18 randomly selected vaccination centers, where mothers visited these centers to vaccinate their children. Women who had live births within the last six months were eligible to participate in the study. However, women who: had any disabling condition, were under any psychiatric treatment, had stillbirths, or pregnant were excluded. Self-administered questionnaires including socio-demographic characteristics, recent obstetric history, the Edinburgh Postnatal Depression Scale, and the SF-12, were completed by 658 women with a response rate of $90.6 \%$. The prevalence of PPD was $45.9 \%$ (CI: $42.1 \%-49.8 \%$ ). Binary logistic regression analysis revealed that low educational level, unplanned pregnancy, no breastfeeding, and past history of PPD were significant determinants to PPD. Moreover, multiple linear regression analysis demonstrated a significant inverse association between PPD and HRQOL (overall, physical and mental health domains). One unit increase in PPD mean total score was associated with reduction in HRQOL overall, physical and mental health domains mean total scores by $1.35,1.23$, and 1.46 respectively. Appropriate measures should be implemented to prevent PPD and its deleterious effects both on mothers and children. Further research, particularly qualitative studies, to explore cultural correlates of PPD in Kuwait is needed.
\end{abstract}

Keywords: postpartum depression, breastfeeding, health related quality of life, kuwait, unplanned pregnancy
Volume I Issue I - 2017

\begin{abstract}
Nour Alhamdan, Abdulrahman Ajaj, Fatemah Alali, Hanan E Badr

Department of Community Medicine and Behavioral Sciences,
\end{abstract} Kuwait University, Kuwait

Correspondence: Hanan E Badr, Department of Community Medicine and Behavioral Sciences, Kuwait University, Kuwait, Tel +965-2463-6576, Fax +965-2533-8948,

Email hanan@hsc.edu.kw

Received: July 17, 2017 | Published: August 23, 2017
Abbreviations: PPD, prevalence of postpartum depression; HRQOL, health related quality of life; WFMH, world federation of mental health; EPDS, edinburgh postnatal depression scale; CI, confidence interval

\section{Introduction}

Giving birth to a new baby is expected to be a pleasurable and satisfactory experience; but some mothers experience some emotional difficulties. It has been shown that the risk of Post-Partum depression (PPD) increases during the first ninety days after delivery and continues for almost two years. About 10 to $20 \%$ of mothers in the first year after delivery suffers from PPD, however, only $50 \%$ of them with prominent symptoms are diagnosed Halbreich \& Karkun. ${ }^{1}$ According to the World Federation of Mental Health (WFMH), ${ }^{2}$ depressive disorders in general are ranked fourth regarding their global burden and are expected to be ranked second by 2020. PPD is generally under identified, underdiagnosed, and undertreated; a condition that can lead to chronic depression, disturbances in the interaction between the mother and her newborn and suicide as well as infanticide in rare cases El-hachem et al. ${ }^{3}$ Evidence suggests that maternal depression has deleterious effects on new mothers, their infants, and family relationships including sexual dissatisfaction Righetti-veltema et al. ${ }^{4}$

They have little verbal communication with their infants, express fewer positive facial emotions and verbal expression, and show less physical affection which lead to impaired maternal-child interactions, including visual and vocal interactions. ${ }^{4}$ In addition, these infants suffer from poorer physical growth Husain et al., ${ }^{5}$ lower cognitive development, more behavioral problems, and a higher risk of psychiatric disorders during adolescent years than those belonging to non-depressed mothers Pawlby et al. ${ }^{6}$ Quality of life (QOL) is a multidimensional concept that affects performance of the individual in physical, psychological, social, and spiritual aspects of life and can be affected by political, cultural, economic, and spiritual beliefs Ioannidis et al. ${ }^{7}$ Several factors affect QOL such as delivery, physical, mental, and social factors Jansen et al. ${ }^{8}$ Women during the postpartum period experience many physiological, social, and psychological changes; therefore, they need more attention during this period regarding the impact on their QOL Pillitteri. ${ }^{9}$ Assessing QOL in this period will allow women to make self-evaluation of their own postpartum situation and will assist healthcare providers with further promotion of women's and infants' health. ${ }^{10}$

Kuwait is one of the Gulf region countries with a 4.4 million population. Nationals comprise about $31.0 \%$ with almost equal gender distribution and the rest of population are expatriates who reside in the country either alone or with their families for work purposes (PACI). ${ }^{11}$ The body of literature shows scarce information about PPD in Kuwait and in the Gulf region in general. Therefore, this study helps fill the gap of knowledge about Kuwait in this health topic and aids policy makers and health planners to set policies and strategies that are necessary regarding this area. This study aimed to access the prevalence of PPD in Kuwait among women in the first six months after delivery and their health related quality of life, to examine determinants of PPD and the association between PPD and women's health related quality of life (HRQL). 


\section{Methods}

\section{Study design and participants}

A cross-sectional study was conducted among a convenience sample of 658 postpartum women with a response rate of $90.6 \%$. The sample was collected from 18 randomly selected vaccination centers, three in each of the six governorates of Kuwait. Participants were eligible to be included in the study if their age was 21-50 and had a live birth in the past 6 months (PPD is more prominent during these months). On the other hand, women were excluded if they were pregnant, had a stillbirth in the last six months, had a physical disability, or were under treatment from any psychiatric problem. The study was carried out between December 2015 and March 2016.

\section{Ethical consideration}

The study was approved by the Health Sciences Center Ethical Committee for Students Research and the Ministry of Health. Moreover, a signed informed consent was attained from each participant prior to data collection.

\section{Data collection instrument}

A self-administered questionnaire divided into four sections was used. The first section inquired about participants' socio-demographic characteristics such as age, nationality, marital status, and education level. The next section covered questions related to the history of recent pregnancy, delivery and its outcome. These included presence of difficulties during pregnancy such as preeclampsia and gestational diabetes, nature of delivery, weeks of gestation, presence of difficulties in delivery such as use of instruments and presence of postpartum bleeding. Regarding the delivery outcome, it covered data about gender, rank of the baby, the newborn health and weight, and breastfeeding. In addition, past history of PPD was also inquired about. The third part of the questionnaire included the Edinburgh Postnatal Depression Scale (EPDS) Cox ${ }^{12}$ which contained 10 item questions. Responses were scored on a 4-point Likert scale ranging from 0-3 with a total score range of 0-30. The Arabic version of the questionnaire was validated by Ghubash et al. ${ }^{13}$

According to ${ }^{12}$ recommendation when using the EPDS in primary health care settings, mothers who scored 12 and above were identified as suffering from PPD. The last section of the study tool was the Health Related Quality of Life (HRQL) questionnaire (SF-12) Ware et al. ${ }^{14} \mathrm{HRQL}$ questionnaires provided a valuable and complementary insight into patients' perspective of the impact of disease on daily life. It described the degree of general physical health status and mental health distress. The HRQL generated two major domains: general physical health status and mental health distress. Recoding of the items was performed to have an equivalent value from 0-100. A total mean score and separate summary mean scores were obtained for each of the physical and mental domains. The higher scores indicated better level of HRQL. Reliability of the Arabic version of the questionnaire was established previously Coons et al. ${ }^{15} \&$ Sheikh et al. ${ }^{16}$

\section{Statistical methods}

Data were entered and analyzed using the Statistical Package for Social Sciences (SPSS) version 23 (IBM, USA). To test the association between the dependent variable, PPD and sociodemographic factors and current obstetric history of participants, Chisquare test was calculated. However, student's t-test was computed to examine the difference in means of HRQL overall and physical and mental health domains between two groups of categorical variables. Pearson's Correlation test was computed to test the correlation between the overall and the sub-scales scores of HRQL with the PPD total score after testing all the mean scores and sub-scores for normality. Multivariate logistic regression analysis was used to investigate the association between PPD (binary outcome variable) and different independent variables. According to the cut-off point, women with PPD were given a score of "1" and those without PPD were given a score of "0". Also, a multiple linear regression models were performed to examine the association between the dependent variable, HRQOL overall, physical as well as mental health domains and the independent variables together with PPD total mean score. All the dependent variable HRQL domains were tested for normal distribution before employing the linear regression models. A $\mathrm{p}$ value of $<0.05$ and confidence interval [CI] of $95 \%$ were considered significant.

\section{Results}

The mean age of participants was $28.95 \pm 4.9$ years and the prevalence of PPD was $45.9 \%$ (95\% CI: $42.1 \%-49.8 \%$ ). The association between socio-demographic characteristics and recent obstetric history of the participants and PPD is illustrated in Table 1. PPD was identified significantly more among participants who had a history of PPD (57.6\%) than among those who didn't report these events. In addition, mothers who had an unplanned recent pregnancy scored higher PPD than their correspondents who had a planned pregnancy $(51.7 \%$ vs. $41.8 \%$ respectively, $\mathrm{p}=0.013$ ). PPD was also reported higher among participants who had difficulties during pregnancy or delivery $(51.7 \%$, $\mathrm{p}=0.007$ and $50.8 \%, \mathrm{p}=0.05$ respectively) than their counterparts who did not. Moreover, PPD was reported the highest among those who did consider breastfeeding at all $(60.0 \%)$, followed by mothers who employed mixed feeding (44.9\%) compared to those who practiced exclusive breastfeeding $(42.4 \%), \mathrm{p}=0.026$.

Table I Association between Socio-Demographic Characteristics and Recent Obstetric History of Mothers who had Deliveries in the Past Six Months with Postpartum Depression (PPD) in Kuwait (N=658) (Row Wise Percentage)

\begin{tabular}{|c|c|c|c|c|c|}
\hline \multirow{2}{*}{ Characteristic } & \multirow{2}{*}{$\begin{array}{c}\text { Total } \\
\mathbf{n}^{\mathrm{a}}\end{array}$} & \multicolumn{3}{|c|}{ Women with PPD } & \multirow[t]{2}{*}{ p-Value ${ }^{c}$} \\
\hline & & (\%) & $\mathbf{n}$ & (\%) & \\
\hline \multicolumn{6}{|l|}{ Age } \\
\hline$\leq 25$ & 173 & -27.1 & 73 & -42.2 & \\
\hline $26-30$ & 252 & -39.4 & 124 & -49.2 & 0.36 \\
\hline$>30$ & 214 & -33.5 & 98 & -45.8 & \\
\hline
\end{tabular}


Table Continued....

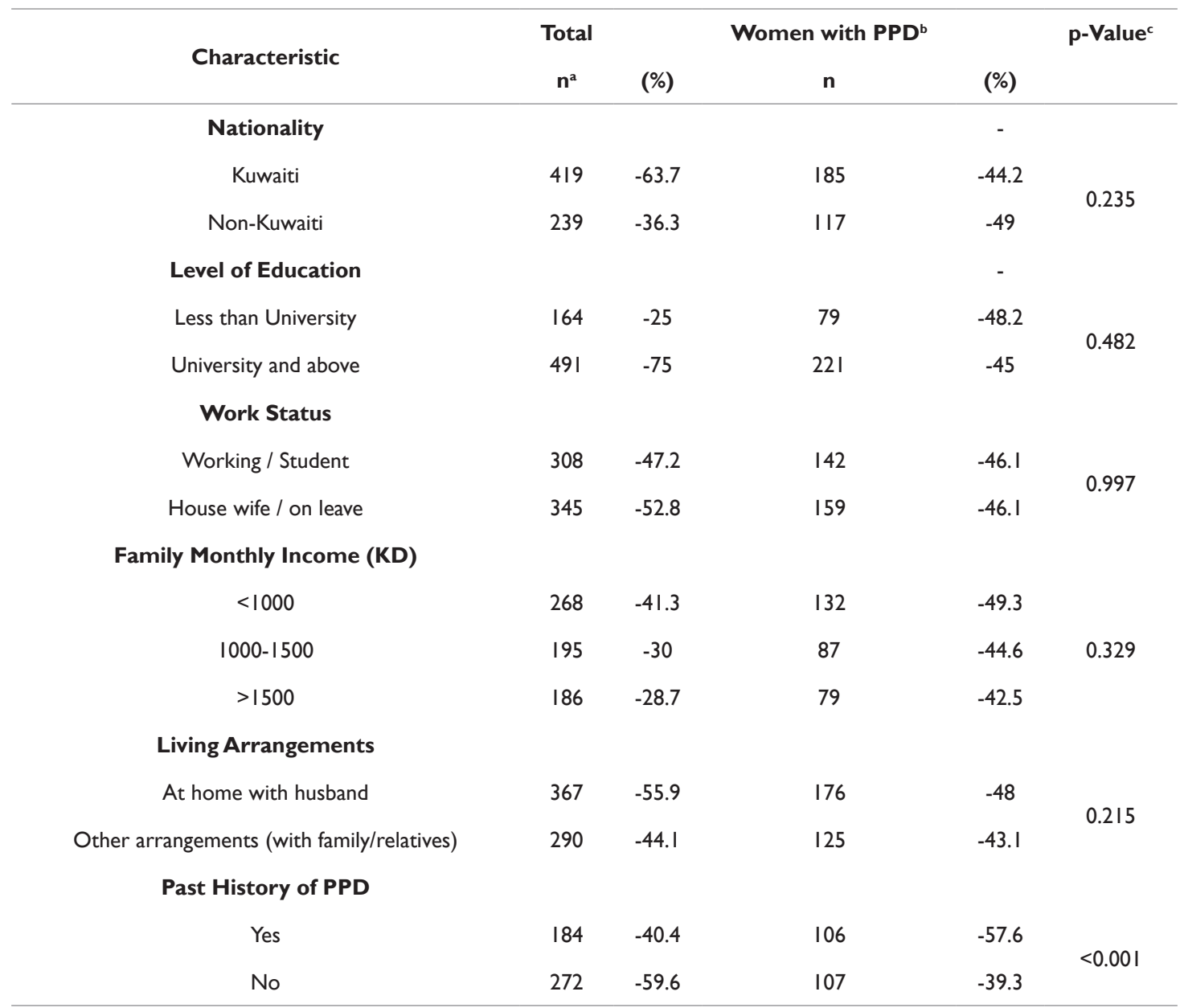

Characteristic

Total

Current Pregnancy and Delivery

$\mathbf{n}^{\mathbf{a}}$

(\%) $n$

(\%)

Planned Pregnancy

\begin{tabular}{|c|c|c|c|c|c|}
\hline Yes & 397 & -60.5 & 166 & -41.8 & \multirow{2}{*}{0.013} \\
\hline No & 259 & -39.5 & 134 & -51.7 & \\
\hline \multicolumn{6}{|l|}{ Gestational Age } \\
\hline Premature term ( $<38$ weeks) & 205 & -33.3 & 100 & -48.8 & \multirow[t]{2}{*}{0.424} \\
\hline Full term & 410 & -66.7 & 186 & -45.4 & \\
\hline \multicolumn{6}{|c|}{ Difficulties During Pregnancy } \\
\hline No & 360 & -54.7 & 148 & -41.1 & \multirow{2}{*}{0.007} \\
\hline Yes & 298 & -45.3 & 154 & -51.7 & \\
\hline \multicolumn{6}{|l|}{ Mode of Delivery } \\
\hline Natural & 426 & -64.9 & 191 & -44.8 & \multirow{2}{*}{0.463} \\
\hline$C($ section & 230 & -35.1 & 110 & -47.8 & \\
\hline \multicolumn{6}{|c|}{ Type of Hospital Mother gave birth in } \\
\hline Governmental & 298 & -45.4 & 136 & -45.6 & \multirow{2}{*}{0.878} \\
\hline Private & 359 & -54.6 & 166 & -46.2 & \\
\hline
\end{tabular}


Table Continued....

\begin{tabular}{|c|c|c|c|c|c|}
\hline \multirow{2}{*}{ Characteristic } & \multicolumn{2}{|c|}{ Total } & \multicolumn{2}{|c|}{ Women With PPD } & \multirow[t]{2}{*}{ P-Value } \\
\hline & $\mathbf{n}^{\mathbf{a}}$ & (\%) & $\mathbf{n}$ & $(\%)$ & \\
\hline \multicolumn{6}{|c|}{ Difficulties during Delivery } \\
\hline Yes & 405 & -61.6 & 174 & -43 & \multirow{2}{*}{0.05} \\
\hline No & 252 & -38.4 & 128 & -50.8 & \\
\hline \multicolumn{6}{|c|}{ Family Support During Postpartum Period } \\
\hline Yes & 557 & -88.4 & 262 & -47 & \multirow{2}{*}{0.747} \\
\hline No & 76 & -11.6 & 36 & -47.4 & \\
\hline \multicolumn{6}{|c|}{ Outcome of this Pregnancy Number of Newborns } \\
\hline I & 620 & -94.2 & 286 & -46.1 & \multirow{2}{*}{0.629} \\
\hline$\geq 2$ & 38 & -5.8 & 16 & -42.1 & \\
\hline \multicolumn{6}{|l|}{ Gender of Newborn } \\
\hline Male & 354 & -54 & 155 & -43.8 & \multirow{2}{*}{0.243} \\
\hline Female & 302 & -46 & 146 & -48.3 & \\
\hline \multicolumn{6}{|l|}{ Rank of Baby } \\
\hline I & 200 & -31.2 & 92 & -46 & \multirow{4}{*}{0.782} \\
\hline 2 & 175 & -27.3 & 83 & -47.4 & \\
\hline 3 & 128 & -20 & 54 & -42.2 & \\
\hline$\geq 4$ & 138 & -21.5 & 66 & -47.8 & \\
\hline \multicolumn{6}{|c|}{ Weight of Newborn (Kg) } \\
\hline$<2.5$ & 92 & -14.4 & 44 & -47.8 & \multirow{3}{*}{0.782} \\
\hline $2.5(4.0$ & 538 & -83.9 & 245 & -45.5 & \\
\hline$>4.0$ & 11 & $(1.70$ & 6 & -54.5 & \\
\hline \multicolumn{6}{|c|}{ Health Status of the Newborn } \\
\hline Healthy & 489 & -74.3 & 217 & -44.4 & \multirow{2}{*}{0.183} \\
\hline Not Healthy & 169 & -25.7 & 85 & -50.3 & \\
\hline \multicolumn{6}{|c|}{ Breastfeeding of the Newborn } \\
\hline Exclusive Breastfeeding & 231 & -35.2 & 98 & -42.4 & \multirow{3}{*}{0.026} \\
\hline Mixed Feeding & 350 & -53.4 & 157 & -44.9 & \\
\hline No Breastfeeding & 75 & -11.4 & 45 & -60 & \\
\hline
\end{tabular}

aThe numbers may not add to total because of missing data.

'PPD: mothers scored $\geq 12$ in the Edinburgh Postnatal Depression scale.

${ }^{c} \mathrm{p}$ (value: between women with PPD and those without.

For HRQOL overall, physical, and mental health domains, the mean scores were 53.7, 54.5 and 52.9 respectively. The association between PPD and the overall health related quality of life (HRQL), physical, and mental health domain mean scores are displayed in Figure 1. HRQL overall, physical and mental health domain mean scores were significantly lower $(\mathrm{p}<0.0001$ for each) among women with PPD (47.4 $\pm 10.3,48.7 \pm 15.5$, and $46.0 \pm 11.1$ respectively) than those without PPD $(59.2 \pm 13.1,59.5 \pm 16.8$, and $58.7 \pm 14.2$ respectively). In addition, Pearson's correlation test showed linear negative association between HRQL overall, mental and physical health domain scores and PPD

total score (Correlation Coefficient $(r)=-0.443,-0.442$, and -0.316 respectively at $\mathrm{p}<0.0001$ for each). The binary logistic regression of significant correlates associated with PPD amid women who had live births in the past six months in Kuwait is presented in Table 2.

Lower level educated participants were 2.24 times more likely to report PPD compared to their counterparts with a higher educational level of university or above (CI: $1.11-4.51, \mathrm{p}=0.024)$. Also, mothers who had unplanned pregnancies were more than two times at risk of PPD compared to those who planned for their pregnancies. Furthermore, the odds of having PPD among non-breastfeeding 
mothers were 3.4 times compared to mothers who experienced exclusive breastfeeding. Besides, participants who had a past history of PPD were almost two times more likely to report PPD relative to those who didn't have a history of PPD. The multiple linear analysis of association between the dependent HRQL and independent PPD mean scores after adjustment for participants' socio-demographic features and recent obstetric history and its outcome isillustrated in Table 3. PPD total mean score stood as an independent predictor $(\mathrm{p}<0.001)$ to HRQL overall, physical, and mental health domain mean scores. The table revealed that a one unit increase in PPD total mean score was significantly associated with a decrease in: the overall HRQL mean score by 1.32 , the physical health domain mean score by 1.24 , and the mental health domain mean score by 1.39 .

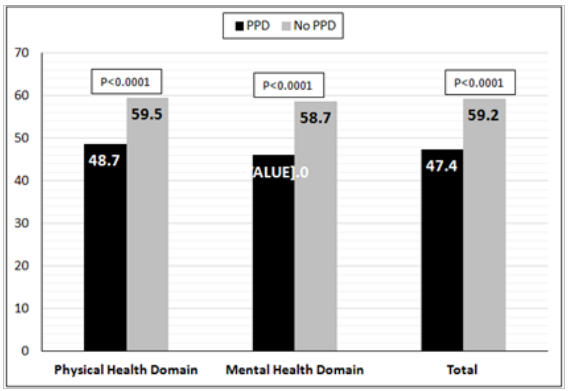

Figure I: Association between Postpartum Depression (PPD) Mean Score and Health Related Quality Of Life (HRQOL) Overall, Physical and Mental Health Domains Mean Scores.

Table 2 Binary Logistic Regression of Significant Factors Associated With Postpartum Depression (PPD) Among Mothers Who Had Deliveries in the Past Six Months in Kuwait $(\mathrm{N}=658)$

\begin{tabular}{|c|c|c|c|c|c|c|c|}
\hline \multirow{2}{*}{ Characteristic } & \multirow{2}{*}{ Subgroup $n$} & \multicolumn{2}{|c|}{ Prevalence of PPD } & \multicolumn{4}{|c|}{ Adjusted Odds Ratio } \\
\hline & & $\mathbf{n}$ & (\%) & $\mathbf{P}$ & OR & {$[95 \% \mathrm{Cl}]$} & $\mathbf{P}$ \\
\hline \multicolumn{8}{|l|}{ Level of Education } \\
\hline University and above & 491 & 221 & -45 & 0.482 & 1 & [Reference] & \multirow{2}{*}{0.024} \\
\hline Less than University & 164 & 79 & -48.2 & & 2.24 & {$[\mathrm{I} . \mathrm{II}(4.5 \mathrm{I}]$} & \\
\hline \multicolumn{8}{|l|}{ Planned Pregnancy } \\
\hline Yes & 397 & 166 & -55.3 & 0.013 & 1 & [Reference] & \multirow{2}{*}{0.008} \\
\hline No & 259 & 134 & -44.7 & & 2.1 & {$[1.22(3.60]$} & \\
\hline \multicolumn{8}{|c|}{ Breastfeeding of the Newborn } \\
\hline Exclusive Breastfeeding & 231 & 98 & -32.7 & 0.026 & 1 & [Reference] & \multirow{3}{*}{$\begin{array}{l}0.318 \\
0.011\end{array}$} \\
\hline Mixed Feeding & 350 & 157 & -52.3 & & 1.33 & {$[0.76(2.31]$} & \\
\hline No Breastfeeding & 75 & 45 & -15 & & 3.4 & {$[1.32(8.79]$} & \\
\hline \multicolumn{8}{|l|}{ Past History of PPD } \\
\hline No & 272 & 107 & -50.2 & $<0.001$ & 1 & [Reference] & \multirow{2}{*}{0.022} \\
\hline Yes & 184 & 106 & -49.3 & & 1.97 & [I.10(3.5I] & \\
\hline
\end{tabular}

aModel I: Covariates include age, nationality, level of education, working status, family monthly income, and living arrangements.

bModel 2: Covariates in the above model and past history of PPD, planned pregnancy, gestational age, difficulties during pregnancy, difficulties during delivery, mode of delivery, and breastfeeding of the new born.

Table 3 Multiple Linear Regression of Association between Health Related Quality Of Life (HRQOL), Physical Health Domain (PHD), Mental Health Domain (MHD), and PPD Total Mean Score Among Mothers who had Deliveries in the Past Six Months in Kuwait $(\mathrm{N}=658)$

\begin{tabular}{|c|c|c|c|c|c|c|c|}
\hline \multirow{2}{*}{ Outcome } & \multirow{2}{*}{ Sub-group $n$} & \multicolumn{3}{|c|}{ Crude Difference in Mean Scores } & \multicolumn{3}{|c|}{ Adjusted Difference in Mean Scores } \\
\hline & & Difference & {$[95 \%$ C.I. $]$} & P-Value & Difference & {$[95 \%$ C.I. $]$} & P-Value \\
\hline $\begin{array}{l}\text { Overall HRQOL mean score } \\
\text { PPD }\end{array}$ & 302 & -1.35 & {$[-1.54--1.17]$} & $<0.001$ & -1.32 & {$[-1.53--1.10]$} & $<0.001 \mathrm{c}$ \\
\hline $\begin{array}{l}\text { Physical Health Domain mean } \\
\text { score of HRQOL PPD }\end{array}$ & 302 & -1.23 & {$[-1.48--0.98]$} & $<0.001$ & -1.24 & {$[-1.55--0.94]$} & $<0.001 \mathrm{c}$ \\
\hline $\begin{array}{l}\text { Mental Health Domain mean } \\
\text { score of HRQOL PPD }\end{array}$ & 302 & -1.46 & {$[-1.65--1.26]$} & $<0.001$ & -1.39 & {$[-1.63--1.16]$} & $<0.001 \mathrm{c}$ \\
\hline
\end{tabular}

a Model I: Covariates included age, nationality, level of education, working status, family monthly income, and living arrangements.

bModel 2: Covariates in above model and past history of PPD, planned pregnancy, gestational age, difficulties during pregnancy, difficulties during delivery, mode of delivery, and breastfeeding of the new-born.

cModel 3: Covariates in above models and PPD mean score. 


\section{Discussion}

This cross-sectional study among 658 women in the first six months post-delivery revealed a prevalence of $45.9 \%$ PPD. The body of literature showed a big diversity in regards to prevalence of PPD. For example, Alasoom \& Koura $^{17}$ reported that globally, PPD is prevalent in a range from $0.5 \%$ to $60 \%$ in Asian countries. Moreover, a literature search conducted between 2005 and 2014 identified 203 studies, where the prevalence of PPD varied from $1.9 \%$ to $82.1 \%$ in developing countries and from $5.2 \%$ to $74.0 \%$ in developed countries. Another study that included 59 studies from North America, Europe, Australia, and Japan estimated the prevalence of PPD as $13 \%, .^{18}$ Regarding Arab countries, the prevalence of PPD in this study ( $\approx 46 \%)$ was higher in comparison to studies among Arab women, such as $22 \%$ in the United Arab Emirates and 21\% in Lebanon. This might be due to variations in the examined length of the postnatal period. The earlier the assessment in the postnatal period, the more the likelihood to find a higher percentage of depressed females. ${ }^{19}$

\section{Factors correlated with PPD}

An important finding in this study was the association between a lower level of education and PPD. Although level of education was not significantly associated with PPD on the bivariate level of analysis, the influence of this factor showed its significant association with PPD after adjusting for confounders. This finding is consistent with a previous studies in Lebanon Chaaya et al., ${ }^{18}$ in Italy Grussu \& Quatraro et al. ${ }^{28}$ and in Iran Mazahiri et al.. ${ }^{20}$ In this regards, less educated women ought to be considered as a vulnerable group to face unpleasant delivery consequences and should be focused for close follow-up, and more care in their postpartum period. In addition, unplanned pregnancy as a predictor for PPD was an important finding in this study. This result matched with the results of preceding studies conducted in Saudi Arabia, ${ }^{21}$ and in Turkey Karaçam et al. ${ }^{21}$ Pregnancy and childbirth are considered a pathological stress to a woman, and if the pregnancy is unwanted, the maternal stress is multiplied and accompanied with many physical and psychological complications for the mother Karaçam et al. ${ }^{21}$ Efforts should be made to enhance family planning programs to decrease the probability of unplanned pregnancy to avoid its negative consequences on the mother and maybe for the baby.

Equally, breastfeeding in this study was associated with absence of PPD. This interesting finding is consistent with the results of Tashakori et al., ${ }^{22}$ who reported that some psychosocial and obstetric factors might increase the risk of developing PPD such as lack of breastfeeding. Moreover, the negative effect of PPD on the duration of breastfeeding was concluding. ${ }^{23}$ On the other hand, Dashti et al. ${ }^{23}$ reported that the practice of breastfeeding in Kuwait showed low interest and only $10.5 \%$ of infants receive exclusive breastfeeding, despite the high rate of initiation (92.5\%).

This might explain the finding of this study. Pre-lacteal feeding is a norm in the Kuwaiti culture. The speedy economic development of the country after oil discovery encouraged Kuwaiti mothers to depend on home helpers in raising the newborns, including feeding them by artificial means. Efforts in implementation of the Baby Friendly Hospital Initiative (BFHI) in Kuwait showed some improvement of breastfeeding practices Perez-Escamilla et al. ${ }^{24}$ However, it requires a long time for cultural habits to switch to breastfeeding. Accordingly, policy makers ought to strengthen and encourage breastfeeding awareness programs very early in a female's life, maybe starting in high schools, to increase awareness about the importance of breastfeeding and its protective effects both to the mother and her baby. Furthermore, the study also revealed that past history of PPD was a predictor for the current PPD. This was an expected result and is consistent with a previous study, which emphasized an evidence of a connection between previous depression or other psychiatric illness and PPD Cohen et al. ${ }^{20}$

\section{PPD and HRQOL}

The negative association between PPD and woman's HRQOL and its physical and mental health domains was an interesting finding in this study, which is concluded in previous studies, Ferreira et al..$^{25-29}$ This vital finding should be utterly consider early detection of PPD by caregivers. Impaired mothers' QOL, particularly in the postpartum period, might drive the mother to several and serious health consequences that could have deleterious effects on mother and the child. More research is needed to dig in depth about the role of social support in alleviating the harmful effects of PPD. Some limitations were encountered in this study that should be highlighted. The nature of the study design as cross-sectional rendered the causation relationship difficult to be established; and mothers with severe PPD who were not able to visit the vaccination centers were overlooked. ${ }^{30-34}$

\section{Conclusion}

The prevalence of PPD was high among women in Kuwait. It was significantly associated with poor HRQOL. Psycho-demographic factors as well as family planning were significant correlates of PPD. Awareness programs about PPD and encouraging breastfeeding should be implemented in the prenatal, natal and postnatal periods to help early detection and reduction of PPD among women. Such actions aid to avoid negative impact of PPD on women's HRQOL and its adverse effects on the mother and the child. Further research to explore cultural variables that might be associated with PPD particularly qualitative studies in Kuwait is needed.

\section{Acknowledgements}

None.

\section{Conflict of interest}

The authors declare that they have no conflict of interest and Informed consent was obtained from all individual participants included in the study.

\section{References}

1. Halbreich U, Karkun S. Cross-cultural and social diversity of prevalence of postpartum depression and depressive symptoms. J Affect Disord. 2009;91(2-3):97-111.

2. World Federation of Mental Health (WFMH). Depression: a global crisis. World mental health day, October 10 2012, India; 2012. p. 3-32.

3. El Hachem C, Rohayem J, Bou Khalil R, et al. Early identification of women at risk of postpartum depression using the Edinburgh Postnatal Depression Scale (EPDS) in a sample of Lebanese women. BMC Psychiatry. 2014;14:242 p.

4. Righetti Veltema M, Conne Perréard E, Bousquet A, et al. Postpartum depression and mother-infant relationship at 3 months old. $J$ Affect Disord. 2002;70(3):291-306.

5. Husain N, Cruickshank K, Husain M, et al. Social stress and depression during pregnancy and in the postnatal period in British Pakistani mothers: a cohort study. J Affect Disord. 2012;140(3):268-276. 
6. Pawlby S, Sharp D, Hay D, et al. Postnatal depression and child outcome at 11 years: the importance of accurate diagnosis. $J$ Affect Disord. 2008;107(1-3):241-245

7. Ioannidis G, Gordon M, Adachi J. Quality of life in osteoporosis. Nurs Clin North Am. 2001;36:481-489.

8. Jansen AJ, Essink Bot ML, Duvekot JJ, et al. Psychometric evaluation of health-related quality of life measures in women after different types of delivery. J Psychosom Res. 2007;63(3):275-281.

9. Pillitteri A. Maternal \& Child Health Nursing: Care of the Childbearing Childrearing. 7th edition. USA: Lippincott Williams \& Wilkins; 2007. p. $621-640$.

10. Bahrami N, Simbar M, Bahrami S. The effect of prenatal education on mother's quality of life during first year postpartum among Iranian Women: A Randomized Controlled Trial. Int J Fertil Steril. 2013;7(3):169-174.

11. The Public Authority for Civil Information (PACI), Kuwait.

12. Cox J, Holden J. The Edinburgh Postnatal Depression Scale-Authors reply. British Journal of Psychiatry. 2003;182(4):368-368.

13. Ghubash R, Abou Saleh MT, Daradkeh TK. The validity of the Arabic edinburgh postnatal depression scale. Soc Psychiatry Psychiat Epidemiol. 1997;32(8):474-476.

14. Ware J, Sherbourne C. The MOS 36-item short-form health survey (SF-36). I. Conceptual framework and item selection. Med Care. 1992;30(6):473-483.

15. Coons SJ, Alabdulmohsin SA, Draugalis JR, et al. Reliability of an Arabic version of the RAND-36 Health Survey and its equivalence to the US-English version. Med Care. 1998;36(3):428-432.

16. Sheikh K, Yagoub U, Elsatouhy M, et al. Reliability and Validity of the Arabic Version of the SF-36 Health Survey Questionnaire in Population of Khat Chewers-Jazan Region-Kingdom of Saudi Arabia. Applied Research in Quality of Life. 2015;10(1):1-13.

17. Alasoom LI, Koura MR. Predictors of postpartum depression in the eastern province capital of Saudi Arabia. J Family Med Prim Care. 2014;3(2):146-150

18. Chaaya M, Campbell OM, El Kak F, et al. Postpartum depression prevalence and determinants in Lebanon. Arch Womens Ment Health. 2002;5(2):65-72.

19. Cohen LS, Wang B, Nonacs R, et al. Treatment of mood disorders during pregnancy and postpartum. Psychiatr Clin North Am. 2010;33(2):273293.
20. Mohammed ES, Mosalem FA, Mahfouz EM, et al. Predictors of postpartum depression among rural women in Minia, Egypt: an epidemiological study. Public Health. 2014;128(9):817-824.

21. Karaçam Z, Onel K, Gerçek E. Effects of unplanned pregnancy on maternal health in Turkey. Midwifery. 2011;27(2):288-293.

22. Tashakori A, Behbahani AZ, Irani RD. Comparison of prevalence of postpartum depression symptoms between breastfeeding mothers and non-breastfeeding Mothers. Iran J Psychiatry. 2012;7(2):61-65.

23. Dashti M, Scott JA, Edwards CA, et al. Determinants of breastfeeding initiation among mothers in Kuwait. Int Breastfeed J. 2010;5:7-16.

24. Perez-Escamilla R. Evidence based breast-feeding promotion: the Baby-Friendly Hospital Initiative. J Nutr. 2007;137(2):484-487.

25. Barbosa E, Petribu K, Mariano M, et al. Quality of life in postpartum depressed adolescents. Rev Bras Psiquiatr. 2008;30:86-87.

26. Claude de Tychey, Serge Briançon, Joëlle Lighezzolo, et al. Quality of life, postnatal depression and baby gender. J Clin Nurs. 2008;17(3):312322

27. Forman D, Videbech P, Hedegaard M, et al. Postpartum depression: identification of women at risk. British Journal of Obstetrics and Gynecology. 2000;107:1210-1217.

28. Grussu P, Quatraro RM. Prevalence and risk factors for a high level of postnatal depression symptomatology in Italian women: a sample drawn from ante-natal classes. Eur Psychiatry. 2009;24(5):327-333.

29. Rojas G, Fritsch R, Solís J, et al. Quality of life of women depressed in the post-partum period. Rev Med Chil. 2006;134(6):713-720.

30. Pearlstein T, Howard M, Salisbury A, et al. Postpartum depression. Am J Obstet Gynecol. 2002;200(4):357-364.

31. Henderson JJ, Evans SF, Straton JA, et al. Impact of postnatal depression on breastfeeding duration. Birth. 2003;30(3):175-180.

32. Mazaheri MA, Rabiei L, Masoudi R, et al. Understanding the factors affecting the postpartum depression in the mothers of Isfahan city. $J E d u c$ Health Promot. 2014;3:65.

33. Norhayati MN, Hazlina NH, Asrenee AR, et al. Magnitude and risk factors for postpartum symptoms: A literature review. J Affect Disord. 2014; 175:34-52

34. Sadat Z, Taebi M, Saberi F, et al. The relationship between mode of delivery and postpartum physical and mental health related quality of life. Iran J Nurs Midwifery Res. 2013;18(6):499-504. 